LA-UR- $02-6615$

Approved for public release,

distribution is unlimited.

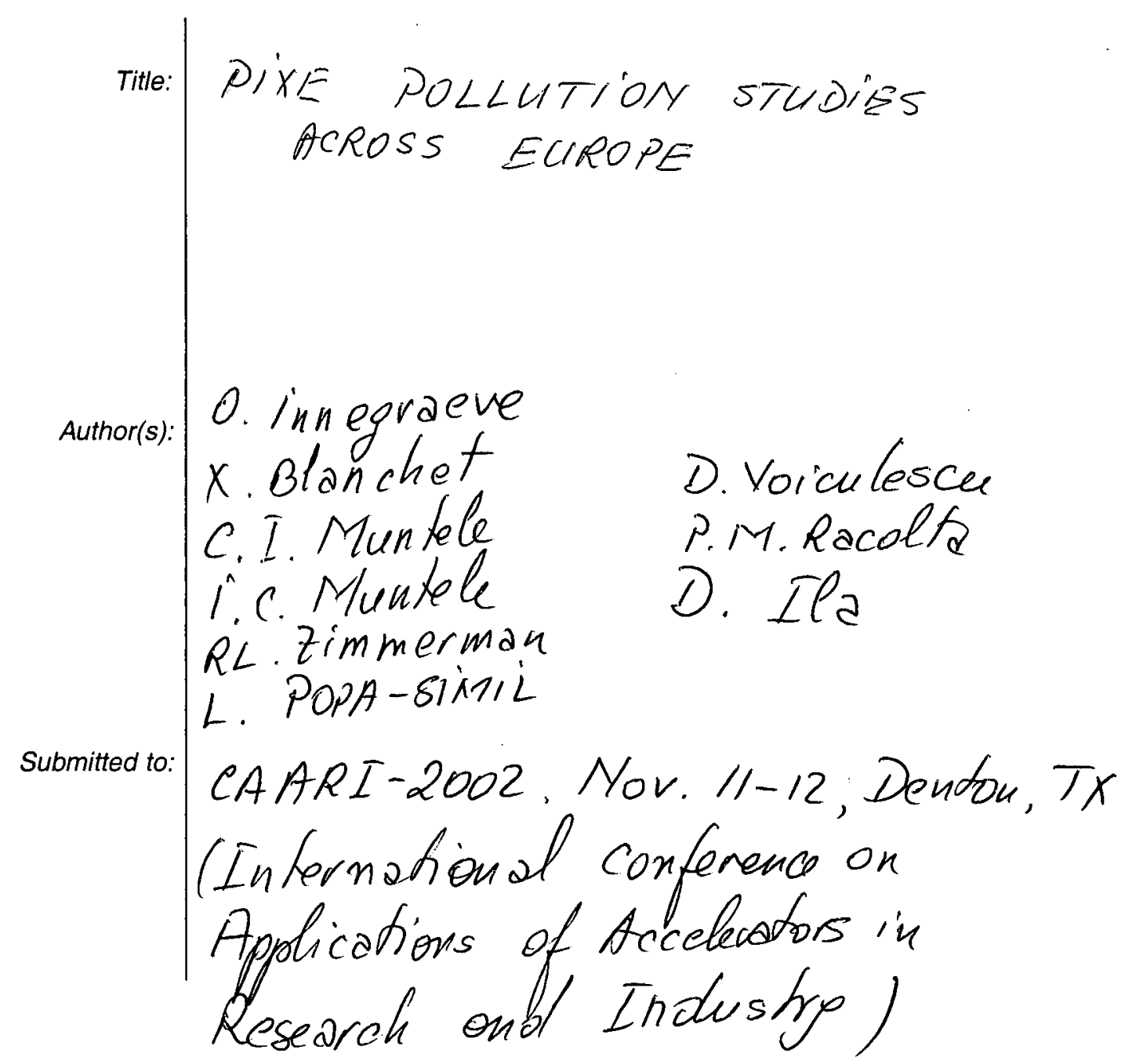

$\int_{\circ \text { Los Alamo }}$

Los Alamos National Laboratory, an affirmative action/equal opportunity employer, is operated by the University of California for the U.S. Department of Energy under contract W-7405-ENG-36. By acceptance of this article, the publisher recognizes that the U.S. Government

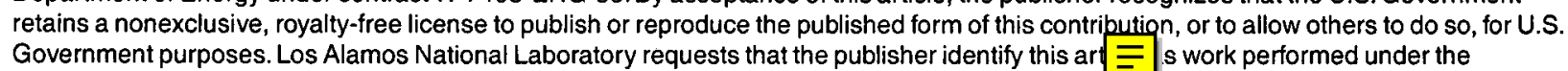
auspices of the U.S. Department of Energy. Los Alamo National Laboratory strongly supports anal .ic freedom and a researcher's right to publish; as an institution, however, the Laboratory does not endorse the viewpoint of a publication or guarantee its technical correctness.

Form $836(8 / 00)$ 


\title{
PIXE Pollution Studies Across Europe
}

\author{
O. Innegraeve $e^{1,2}$, X. Blanchet ${ }^{1,3}$, C. I. Muntele ${ }^{1}$, I. C. Muntele ${ }^{1}$, R. L. \\ Zimmerman $^{1}$, L. Popa-Simil ${ }^{4}$, D. Voiculescu ${ }^{5}$, P. M. Racolta ${ }^{5}$, and D. Ila \\ ${ }^{I}$ Center for Irradiation of Materials, Alabama A\&M University, P. O. Box 1447, Normal, AL. 35762-1447 USA \\ ${ }^{2} 101$ bis Boulevard Clemenceau, $59510 \mathrm{Hem}$, FRANCE \\ ${ }^{3}$ Université Claude Bernard Lyon 1, 43 Boulevard du 11 Novembre 69622 Villeurbanne Cedex, France \\ ${ }^{4}$ Los Alamos National Laboratory, M. S. 319, Los Alamos, NM \\ ${ }^{5}$ National Institute for Physics and Nuclear Engineering, MG-6, Bucharest, Romania
}

\begin{abstract}
We collected vegetation and soil samples from various locations along a route covering Eastern and Western Europe. We measured the level of elemental pollution in different places uniformly spread across the continent to determine which of them may have common sources. To achieve these objectives, samples were collected along the main roads from Romania to Portugal and analyzed using in-air PIXE (Particle-Induced X-ray Emission) [1].
\end{abstract}

\section{INTRODUCTION}

Technological development of the nowadays society and the general human activity have a tremendous impact to the biosphere, sometimes with irreversible changes. Although this impact has been dated from the Neolithic Period, the deterioration of the ecosystem due to pollution, and the corresponding problems, have become increasingly acute during the latter decades of the $20^{\text {th }}$ century due to their cumulative aspect over time. Major factors interfering with the biosphere are the intensive and extensive industrial development, as well as the departure from the traditionally organic agriculture towards the heavy usage of chemicals as fertilizers and pesticides.

The elemental contamination of the soil has no direct effect on humans. However, plants growing on contaminated soil can absorb the contaminants either because of their similar chemical behavior to other minerals needed for growth (i. e. $\mathrm{Ge}$ for $\mathrm{Si}$ ) or because their chemical interaction to other mineral compounds taken naturally by plants (i. e. $\mathrm{Cu}$, which is mainly interacting with organic compounds of low molecular weight and with proteins). The plants represent the link between the soil pollutants and their passage to the humans through the food chain.

The goal of this experiment was to investigate for the relative content of heavy elements in soil samples collected from on the roads and away (more than 20 m) from roads, as well as the heavy element intake of local vegetation. Preliminary results of this study are presented in this paper.

\section{EXPERIMENTAL SETUP}

To perform this investigation, we modified the existing PIXE station at the Center for Irradiation of Materials (CIM) of Alabama A\&M University such that the proton beam could be extracted in air through a $15 \mu \mathrm{m}$ thickness and $5 \mathrm{~mm}$ diameter aluminum window. The final energy of the proton beam incident on target was about $2 \mathrm{MeV}$. The Si-PIN X-ray detector was thermoelectrically cooled to $-30^{\circ} \mathrm{C}$ and placed at an angle of $100 \mathrm{deg}$. from the beam direction, to avoid the bremsstrahlung from the high energy electrons in target (Figure 1). We acquired X-ray spectra for the same amount of charge integrated for each sample. 
Samples of soil and vegetation were collected in the summer of 1997 from 12 different locations across Europe (Figure 2). The targets for the PIXE analysis were prepared by placing the soil or vegetation samples using double-sided adhesive carbon tape on microscope glass slides. The thick $(0.5 \mathrm{~mm})$ carbon tape masked completely the glass surface from the proton beam, and additional measurements were performed to make sure that no parasitic silicon signal is detected.

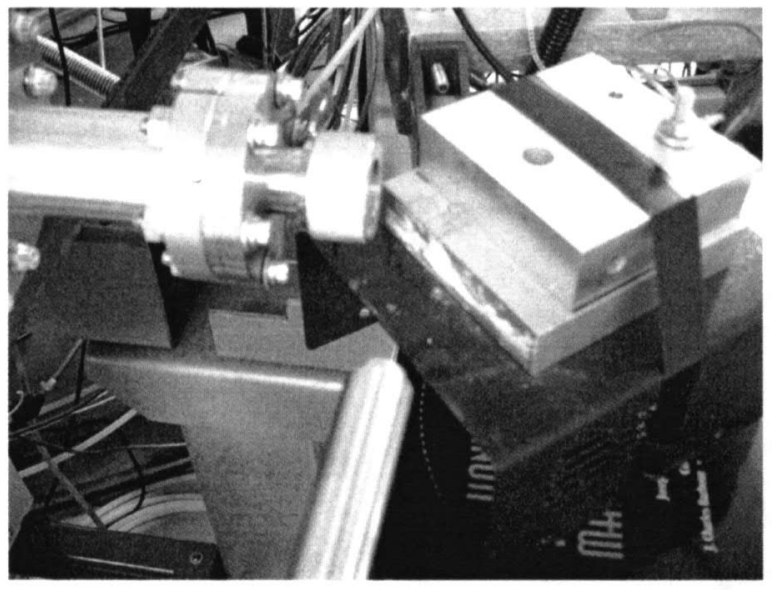

FIGURE 1. The modified PIXE setup, showing the extraction window for the proton beam (top left), the target holder (top right), and the detector head placed at $100 \mathrm{deg}$. from the beam direction (bottom).

\section{RESULTS AND COMMENTS}

The attempt is new, and starts with the idea of creating an image of what happens in the near vicinity of roads, due to various kinds of pollution appearing in this micro-bio-system. Main toxically pollutants considered were $\mathrm{Pb}, \mathrm{Ge}, \mathrm{Zn}, \mathrm{Fe}, \mathrm{Cs}, \mathrm{Cd}$. The values highlighted do not have the character of general or average for the area but are showing the instant values for a specific point and date, and therefore possible to be irreproducible.

Looking at lead (Figure 3) we observe a high amount on the road at location 5 (Perpignan, France), which is unexpected. All the other elements are present in very small amounts, the place being a nice and clean resort at the shore of the Mediterranean Sea. We therefore attribute this result to an accidental accumulation from some past activities. Overall, France roads have small amounts of lead in the soil from both on and off road, but vegetation is quite clean showing that the airborne pollution decreased in the last period of time.

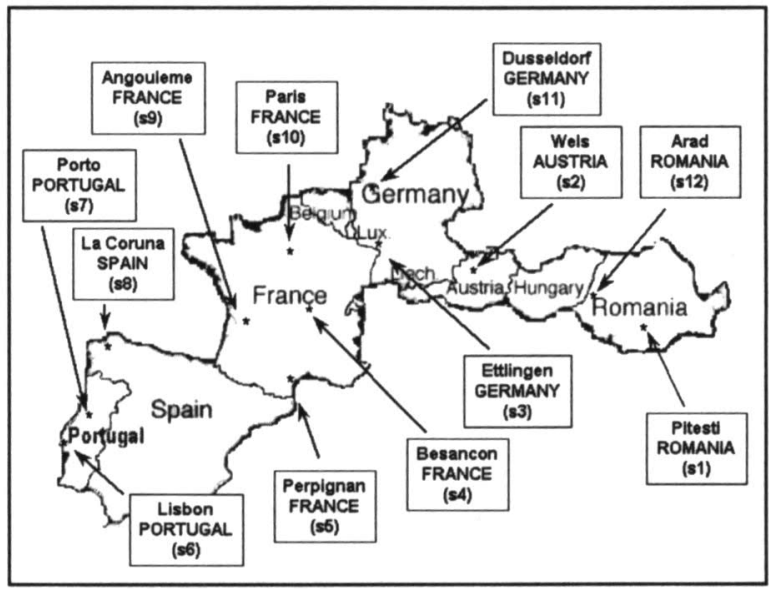

FIGURE 2. European site locations for selected samples.

Besancon is an exception, just like Dusseldorf (Germany), displaying large amounts of lead in vegetation samples. It is already known that plants do not absorb significant amounts of $\mathrm{Pb}$ from soil [3], therefore the source of contamination in these cases has to be airborne $\mathrm{Pb}$ deposited on leaves and then absorbed in cells tissue. It is possible that some chemical industrial emissions more suitable with plants might be present in these regions, or that in the other places lead did not appear in significant amounts in the period 95-97 as to be present in our data.

Germanium comes from vegetation and specific soils, and it was observed in Lisbon, Paris, and Dusseldorf.

Aside from its natural provenience, zinc is coming mainly from traffic, being an oil additive as well as an alloying compound, and is deposited on road by vehicles exhaust, being proportional with the density of traffic. It is widely spread due to the fact that the particulates are small, and have been continuously emitted. We found zinc also on the vegetation samples.

Iron is also coming from vehicles as well as from natural sources (soil compounds), and increased amounts are observed in industrial and high traffic areas as Paris, Dusseldorf, which makes us believe that most of it has artificial provenience (man made objects and activities).

Cesium and cadmium are widely spread, and they have an artificial provenience as well as a natural one. Ocean aerosols as well as power production and other industrial activities can explain the high amounts of $\mathrm{Cd}$ in Lisbon. Cs shows little presence in plants, whereas $\mathrm{Cd}$ is well represented. Although $\mathrm{Cd}$ does not 


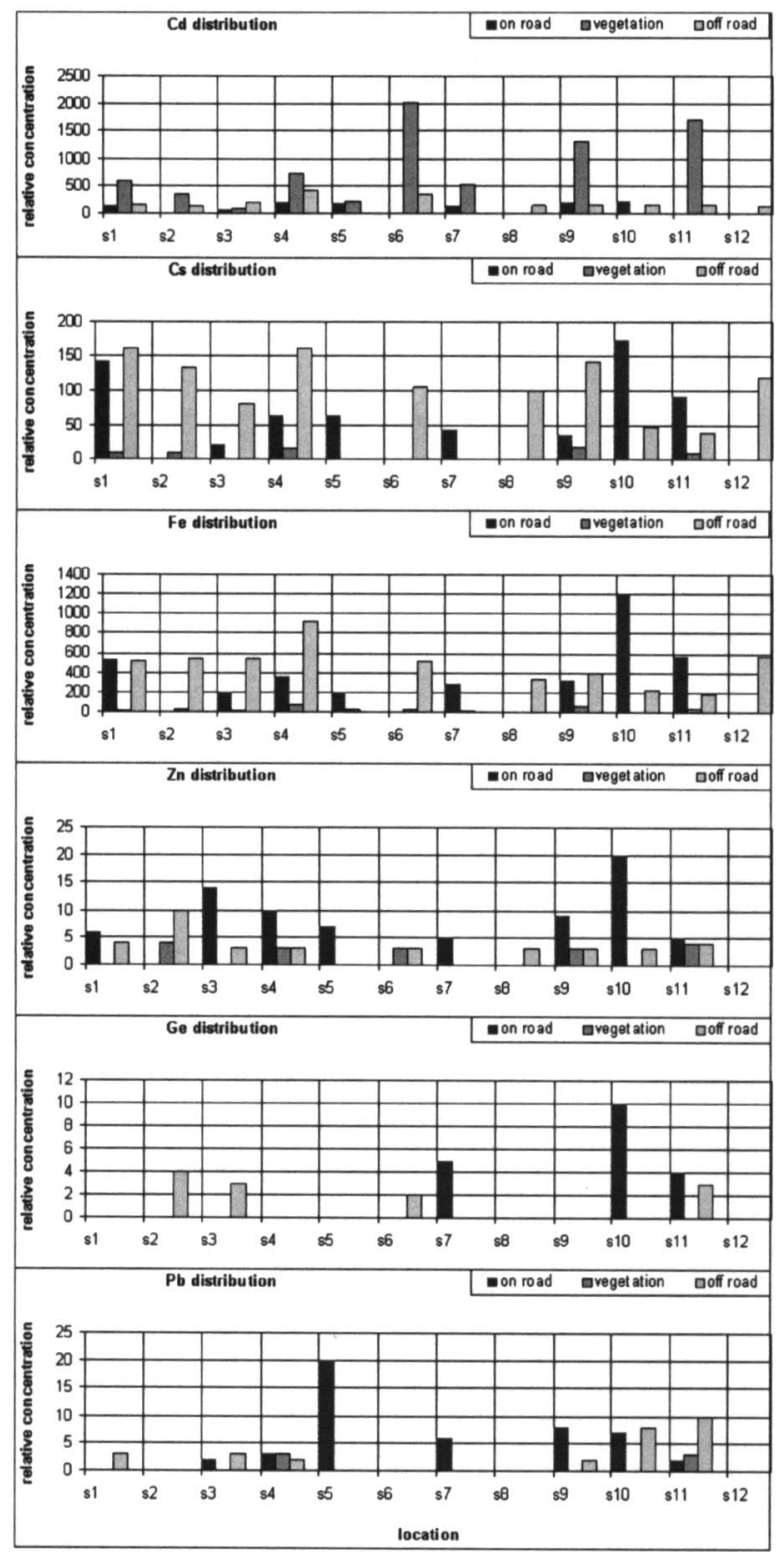

FIGURE 3. Relative concentration of monitored elemental contaminants. play a role in the plants metabolism [2], it is easily absorbed and stored. Since the samples of surrounding soil have little content of this element, we imply that the source is airborne. The charts show that the vegetation is less sensitive to $\mathrm{Cs}$ and $\mathrm{Fe}$, taking amounts specific to their bio-cycle, as opposed to the case for $\mathrm{Cd}$.

\section{CONCLUSIONS}

Measurements have shown the interesting behavior of plants when exposed to different pollutants. Relative distributions of selected elemental contaminants were presented and relatively correlated with the industrial activity and traffic density in the selected regions. These measurements prove the analytic power of ion beam based methods to highlight the most intimate aspects of the ecological system's response to civilization aggression.

The technique has to be further elaborated in order to get more accurate results and to enlarge the spectrum of elements that can be monitored. The methodology is simple, fast, and relatively inexpensive. Work is in progress to develop standard calibration samples in order to extract quantitative results from the analyzed samples.

\section{REFERENCES}

1. Steven A. E. Johansson, John L. Campbell, Klass G. Malmqvist, "Particle Induced X-Ray Emission Spectrometry (PIXE)", John Wiley and Sons Inc., 1995.

2. A. Kabata-Pendias, H. Pendias, "Trace Elements in Soils and Plants", Second Edition, CRC Press, 1992.

3. Zimdahl, R. L., $68^{\text {th }}$ Annual Meeting of the Air Pollution Control Association, 1975, p. 2. 